\title{
Sonhos de um Visionário e suas contribuições para a ética de Kant
}

\author{
Bruno Cunha \\ Doutorando em filosofia na UFMG
}

Resumo: Neste artigo, argumentarei a favor da ideia de que os aspectos fundamentais do sistema da metafísica da moral já estavam presentes na reflexão de Kant contextualizada no período entre 1764-1766. Tendo como referência o texto publicado em 1766, intitulado Sonhos de um Visionário explicados por Sonhos da Metafísica, buscarei demonstrar, a partir da reflexão de Kant sobre 0 mundo espiritual, os primeiros traços de um novo modo de se compreender a metafísica como problema da vontade, que introduzirá, em consequência, as primeiras indicações na literatura referentes às noções de autonomia, liberdade, formalismo, imperativo categórico, reino dos fins e sentimento moral.

Palavras-chave: ética; vontade; autonomia; mundo espiritual; metafísica.
Abstract: In this paper, I argue that the main aspects of the metaphysics of morals were already developed in Kant's thought in 1764-1766. Based on the Dreams of a Spirit-seer elucidated by Dreams of Metaphysics, published in 1766, I will try to demonstrate the first traces of a new understanding about the metaphysics as the problem of the will in Kantian thought from a analysis of the spiritual world. Accordingly, this conception will present the first published evidences about the concepts of autonomy, freedom, formalism, categorical imperative, kingdom of ends and moral sentiment.

Keywords: ethics; will; autonomy; spiritual world; metaphysics.

\section{Considerações Iniciais}

O texto Sonbos de um Visionário explicados por Sonbos da Metafísica, de 1766, é uma publicação bastante excêntrica quando comparada aos trabalhos convencionais de Kant. O primeiro aspecto claramente notável é sua forma de escrita - totalmente distinta do tom acadêmico das outras publicações - caracterizada, sobretudo, pela forma literária e estilística, utilizando-se de recursos tais como a ironia, a sátira e a metáfora. No entanto, talvez o ponto mais insigne do texto não 
esteja propriamente representado em sua forma estilística, mas no motivo real que inspirou as linhas impregnadas de ironia e sarcasmo com as quais Kant expressou seus pensamentos em Sonbos, ou seja, as histórias fantásticas sobre espíritos relatadas por Emanuel Swedenborg1. É muito estranho que Kant tenha se interessado por este assunto ${ }^{2}$. Mas, a despeito de suas motivações mais íntimas, existe um aspecto bem delineado no texto, claramente notável a partir do título, a saber, o paralelismo - traçado entre a metafísica dogmática e o misticismo estabelecido a partir da maneira "desimpedida" de ambas as doutrinas para alcançar evidências sobre o mundo suprassensível.

Os sonhos de um visionário ilustram os sonhos da metafísica porque Kant deseja expressar todo o seu descontentamento com a filosofia das universidades, preocupada em alcançar racionalmente, sem uma justificação adequada, "as propriedades ocultas das coisas" e , ao mesmo tempo, as provas da existência de Deus, da liberdade e da alma humana ${ }^{4}$. Mas, em contrapartida aos esforços empreendidos pelos filósofos da escola, Kant mostra-se cético em relação aos seus objetivos, mostrando-se ciente de nossos limites racionais: "a prudência manda adequar o tamanho dos projetos às forças disponíveis, e, caso não se possa atingir plenamente o grandioso, limitar-se ao mediano" ${ }^{\prime \prime}$. Se, até o momento, constatou-se o fracasso do empreendimento filosófico alemão em alcançar seus objetos fundamentais, isso se deve ao fato de que tais objetos estão além da capacidade de qual-

1. Emanuel Swedenborg foi cientista e homem de estado na Suécia. Em 1745 revelou o seu verdadeiro dom descrito como a capacidade de se comunicar com o mundo dos espíritos. Este dom sublime permitiu-lhe desvendar o sentido intrínseco das coisas do mundo. Swedenborg, assim, assumiu o compromisso de divulgar o sentido oculto contido nas Sagradas Escrituras e revelou muito destes segredos em seu tratado Arcana Coelestia.

2. Os motivos recônditos que aproximaram Kant e Swedenborg serão o assunto de um próximo artigo.

3. KANT, I. Träume eines Geistersebers, erläutert durch Träume der Metapbysik. In: Gesammelte Schriften. Berlim: Preußischen Akademie der Wissenschaften, 1910, vol. II, p. 367.

4. Em referência ao famoso tratado de metafísica de Wolff, que representa bem os objetivos da "metafísica alemã": Vernünftige Gedanken Von Gott, der Welt und der Seele des Menschen, auch alle Dingen Überbaupt [Pensamentos racionais sobre Deus, o mundo e a alma dos homens, bem como sobre todas as coisas em geral].

5. KANT, I. Träume eines Geistersebers, erläutert durcb Träume der Metapbysik, p. 352. 
quer ciência especulativa. Este fato revela que existe um sério problema na filosofia, cuja tarefa adequada, por ora, deveria ser a de "uma ciência dos limites da razão humana", preocupada em estabelecer "com segurança os limites de nossa compreensão"6.

O diagnóstico negativo apresentado no texto, no entanto, não representa um ceticismo definitivo e desmedido. Se existe uma limitação aos assuntos da metafísica, pelas vias de nosso entendimento, em que Kant não fornece nenhuma indicação de uma solução positiva, essa limitação é superada mediante as indicações de um novo modo de se pensar a metafísica, de um maneira positiva e inovadora, a partir da experiência concreta de nossa vontade. De fato, é sabido que este importante insight não viria à luz, de um modo mais elaborado, nos quase vinte anos que se seguiriam até 1785 . No entanto, curiosamente, uma hipótese apresentada como uma sátira, no segundo capítulo de Sonhos, apresenta evidências importantes sobre esta nova maneira de se compreender o problema moral. Embora a mencionada hipótese seja apresentada como uma piada na qual, claramente, Kant deseja ridicularizar o discurso especulativo, o conhecimento que temos de sua ética madura, em acréscimo a outras evidências observadas em cartas e anotações da época, torna possível supor que, implicitamente, não se tratava só disso. Pois, a partir dela, reconhecemos muito do que estaria no sistema elaborado da metafísica da moral. Isso sugere, como defende Schmucker, que o segundo capítulo de Sonhos não apresenta ideias que foram trazidas somente com a mera função especulativa, para "serem repudiadas depois como uma piada teórica. Isto não foi uma sátira. São insights duramente conquistados sobre a essência da experiência ética humana"7. Kant apresenta-nos uma elaboração do esquema de filosofia moral que já havia sido cogitado em meados de 1760 nas anotações conhecidas como Bemerkungen zu den Beobacbtungen über das Gefübl des Schönen und Erbabenen (Anotações às Observações sobre o Sentimento do Belo e do Sublime). Ele nos dá uma antecipação de seu pensamento sobre os primeiros princípios metafísicos da filosofia moral. A carta escrita para Lambert, em dezembro de 1765, fornece-nos boas indicações de que Kant trabalhava com esse tema na época. Diz Kant a Lambert:

6. Idem, ibidem.

7. SCHMUCKER, J. Die Ursprünge der Etbik Kants in seinen vorkritischen Schriften und Reflektionen. Meisenheim: A. Hain, 1961, p. 156. 
Eu noto em meu trabalho que, embora eu tenha muitos exemplos de juízos errôneos para ilustrar minhas teses sobre os erros de procedimento, faltam-me exemplos para mostrar em concreto como o próprio procedimento deve ser. Portanto, a fim de evitar a acusação de que eu estou meramente esboçando um novo esquema filosófico, eu devo primeiro publicar alguns ensaios menores com o conteúdo que eu tenho trabalhado, sendo que os primeiros serão A Fundamentação Metafísica da Filosofia Natural [natürlicben Weltweisheit] e A Fundamentação Metafísica da Filosofia Prática [praktischen Weltweisheit $][\ldots]^{8}$.

Assumindo estas considerações, o objetivo deste artigo é demonstrar, tendo como referência o texto Sonbos de um Visionário - e com o auxílio dos fragmentos conhecidos como Bemerkungen e Reflexionen - a procedência da ideia de que os principais aspectos do sistema da metafísica da moral já estavam desenvolvidos, em certa medida, na reflexão kantiana contextualizada no período entre 1764-1766. Especificamente, serão demonstradas, a partir da reflexão sobre o mundo espiritual, que é apresentada no capítulo dois do texto, (1) as primeiras indicações publicadas referentes aos conceitos de autonomia, liberdade, formalismo e imperativo categórico. (2) Em seguida, indicar-se-á, de acordo com a hipótese do mundo espiritual, a primeira formulação daquilo que viria a ser chamado, na filosofia crítica, de reino dos fins. (3) Por fim, apresentar-se-á os novos contornos adquiridos pelo conceito de sentimento moral, concebido mais de acordo com a perspectiva madura de Kant.

\section{A hipótese do mundo dos espíritos}

\section{a. Os princípios de vida e o mundo espiritual}

Um fragmento da filosofia secreta, para iniciar a comunidade no mundo dos espíritos é o título impregnado de sarcasmo com o qual Kant nomeia o segundo capítulo de Sonbos e se autoriza a deduzir "figuras espirituais [...] destituídas de roupagem corporal naquele crepúsculo que a luz fraca da metafísica faz visível o reino das sombras ${ }^{\prime \prime}$. Toda a ironia que envolve estas linhas iniciais demonstra a intenção de Kant em

8. KANT, I. Briefwechsel. In: Gesammelte Schriften. Berlim: Preußischen Akademie der Wissenschaften, 1910, vol. X, p. 56.

9. KANT, I. Träume eines Geistersebers, erläutert durcb Träume der Metapbysik, p. 329. 
aventurar-se "no perigoso caminho"10 das especulações da metafísica. Seu objetivo consiste em apresentar uma hipótese sobre a existência de um suposto mundo espiritual.

Kant inicia sua meditação enunciando a característica fundamental da matéria, a saber, a extensão, aspecto que pode ser deduzido a partir de "uma definição física que é, ao mesmo tempo, uma definição matemática, que juntas se chamam definição mecânica" ${ }^{\prime \prime 1}$. Diferente da matéria e sua sujeição às leis mecânicas, "como as leis do contato e do choque $^{\prime \prime 12}$, observamos uma espécie de seres que contêm em si o princípio da vida. A atividade interna destes seres mostra sua independência em relação às leis mecânicas, o que nos leva à convicção, se não por meio de uma demonstração científica, mas antes por meio de uma sensação prévia e imediata, da existência de seres imateriais que parecem dotados de "leis causais particulares [...], chamadas pneumatológicas [pneumatisch $]^{\prime 13}$. Observamos que estas substâncias espirituais apresentam-se como naturezas espontâneas que subsistem por si, mesmo em contato com os corpos materiais que formam os seres orgânicos. Se existe na matéria uma necessidade de associação, por que não haveria esta mesma necessidade nas substâncias espirituais a que esta se vincula? Tal ideia leva Kant a supor a possibilidade de estas naturezas subsistentes formarem um grande todo "que se pode chamar de mundo imaterial (mundus intelligibilis)"14. Este todo espiritual, todavia, deve existir sem a mediação dos corpos, pois tal relação "é apenas contingente", ao passo que a relação particular dos seres imateriais é "natural e indissolúvel"15.

A reunião de todos os princípios de vida do mundo nos faz pensar a existência do mundo inteligível em uma "escala enorme, mas desconhecida de seres e naturezas ativas ${ }^{\prime \prime 16}$. Em alguma medida, Kant remete-nos à sua teoria inicial das forças vivas ${ }^{17}$ ao conceber que esta

10. Idem, ibidem.

11. Idem, ibidem.

12. Idem, ibidem.

13. Idem, ibidem.

14. Idem, ibidem.

15. Idem, p. 330 .

16. Idem, p. 329.

17. A doutrina das forças vivas foi o postulado que caracterizou a metafísica inicial de Kant. Visando elaborar uma fundamentação metafísica para a doutrina de Newton, Kant buscou encontrar a conciliação entre algumas noções fundamentais da 
escala enorme de seres não pode ser estabelecida e restringida, com exata certeza, aos seres orgânicos. Diz ele: "[...] é talvez impossível estabelecer seguramente algum dia até quais membros da natureza se estende a vida e quais são os graus dela que de imediato tocam na total ausência de vida"118. O movimento livre, especificamente a execução do arbítrio, é o fenômeno da vida mais evidente e passível de nossa apreensão, fato que não prova indubitavelmente que seja exclusivo no tocante à vida da natureza ${ }^{19}$. Kant reconhece que não há uma prova irrefutável de que os seres orgânicos sejam os únicos portadores da vida. Existe um profundo debate sobre o assunto, exemplificado no antagonismo de duas posições filosóficas vigentes no século XVIII, o Hilozoísmo, que defende a vivificação de tudo, e o materialismo, que mata todas as coisas $^{20}$.

primeira, como as de substância e forças ativas, com os fenômenos empíricos dos quais tratava a segunda. Segundo a doutrina das forças vivas, apresentada desde o primeiro trabalho de Kant, mas, só elaborada de modo efetivo no tratado Física Monadológica de 1756, os corpos são compostos de partes simples, unidades singulares que irradiam força partindo de um ponto central, gerando um efeito que nos permite identificar as características externas da ocupação espacial pela matéria. Para saber mais sobre o assunto, eu indico meu artigo, que ainda será publicado: As consequências de Sonhos de um Visionário para a concepção kantiana da metafísica: o problema do espírito e suas implicações no período pré-crítico.

18. Idem, ibidem.

19. Nesta passagem, Kant refere-se à ambiguidade existente na fronteira entre plantas e animais e à próxima relação de pólipos e zoófitos com as plantas. Kant utiliza-se da concepção de Borhaave para destacar esta perspectiva. Segundo Borhaave, "o animal é uma planta que tem suas raízes no estômago (internamente). Talvez, com a mesma liberdade, um outro pudesse brincar [...] a planta é um animal que tem seu estômago nas raízes (externamente). Por isso, também podem faltar às plantas os órgãos do movimento arbitrário [...]" (KANT, I. Träume eines Geistersehers, erläutert durch Träume der Metapbysik, p. 331). Não há necessidade de tais órgãos nas plantas, pois elas são normalmente mantidas "externamente por forças externas e, mesmo contendo um princípio da vida interno $[\ldots]$, não carece de uma disposição orgânica para a atividade externa arbitrária" (Idem, ibidem).

20. Hilozoísmo é identificado com os fundamentos postos pela filosofia de Pierre-Louis Moreau de Maupertuis e George Ernest Stahls. O materialismo, por sua vez, com os princípios de Frederick Hoffman e Hermann Boerhaave. Segundo Kant, "Maupertuis atribuiu um ínfimo grau de vida às partículas nutritivas orgânicas de todos os animais; outros filósofos não vêem nelas 
As considerações de Kant situam-se nas intensas disputas que perpassam a Europa, no meio do século, sobre a natureza das ciências da vida, sobretudo para enfatizar que o fundamento vital das "criaturas que crescem e se reproduzem" não é algo "absurdo", mas é certamente "indemonstrável" ${ }^{\prime 21}$. Experimentamos as diversas manifestações da vida na natureza, mas não podemos explicá-las. Kant utiliza-se deste argumento para recusar a explicação dos fenômenos através de princípios imateriais. Em sua opinião, este é um "refúgio da filosofia preguiçosa" $^{\prime \prime 2}$, que deve ser evitado mesmo para explicar os fenômenos do mundo e as leis do movimento da matéria. Ao assumir esta posição, Kant vai, claramente, na contramão da ideia presente em sua hipótese das forças vivas representada no "postulado de forças imateriais sem a mediação da matéria [...]", que é um artifício usado para remediar a "[...] tentativa de explicar as coisas pelas causas mecânicas" ${ }^{\prime 23}$. Contudo, Kant admite que, se a filosofia de princípios imateriais é uma filosofia ruim, às vezes ela parece mais perto da verdade do que o pensamento que se atém a fundamentos mecânicos.

b. Os princípios do mundo dos espíritos: vontade, autonomia e liberdade

Segundo a hipótese kantiana, existe a possibilidade de que os princípios imateriais existam, tal como a vida nos demonstra, mesmo que seja impossível constatar como ocorrem e "até onde estende sua eficácia". Somente supõe-se que todos estes princípios imateriais caracterizam-se por sua independência em relação às "condições limitantes das relações dos corpos" e, consequentemente, à "distância dos lugares e dos tempos". No conjunto destes elementos imateriais, que inclui todos os princípios de vida da natureza, Kant supõe estar a alma, o que legitima o pertencimento do homem a "dois mundos simultaneamente ${ }^{124}$.

senão amontoados mortos que só servem para aumentar os componentes da máquina animal" (Idem, p. 330).

21. Idem, p. 331.

22. Idem, ibidem.

23. BEISLER, F. Kant's Intellectual Development. In: GUYER, P. (org.) The Cambridge Companion to Kant. United Kingdom: Cambridge University Press, 1992, p. 45.

24. KANT, I. Träume eines Geistersebers, erläutert durcb Träume der Metapbysik, p. 331. 
O real objetivo de Kant ao empregar o método hipotético-especulativo dentro da investigação começa a ser revelado. Ao situar o problema dentro de uma discussão sobre a alma, este, gradativamente, é deslocado de dentro do âmbito das ciências naturais para o campo da moralidade. Por isso, a constituição sistemática do suposto mundo espiritual é vislumbrada através de uma evidência que não é meramente especulativa, mas é algo verificável no mundo concreto. Diz Kant: "Seria ótimo se a constituição sistemática do mundo dos espíritos, como a representamos, pudesse ser deduzida ou mesmo só inferida com a probabilidade de alguma observação efetiva e geralmente admitida $[\ldots]^{1 / 25}$. Dessa maneira, é o comportamento moral que abre a possibilidade de se vislumbrar uma conjectura sobre o mundo espiritual, no qual a disposição da vontade em direção ao universal permite supor a participação do homem dentro de uma comunidade inteligível de seres.

Kant sugere, assim, um modelo de reflexão sobre a vontade no qual sua prioridade repousa no interesse público ou moral em detrimento do privado. Nesta reflexão, sobretudo, ele deseja destacar uma tendência peculiar da vontade em transcender sua condição particular a partir da orientação de uma regra interna que encontra sua referência não nas próprias inclinações, mas na vontade de outros seres racionais. Desse modo, Kant observa que uma das forças poderosas presentes no íntimo do homem indica a existência de uma propensão que, em detrimento da necessidade privada, orienta sua vontade em direção à de outros seres racionais. "Quando reportamos coisas externas à nossa necessidade [...] um poder secreto nos coage a orientar nossa intenção para o bem de outros ou de acordo com o arbítrio de estranhos [fremder Willkür]". ${ }^{26}$ Esta propensão pode ser suficientemente notada a partir do conflito de duas forças em seu interior, a saber, o altruísmo, que mostra a tendência de sua vontade em transcender as suas carências e inclinações, e o egoísmo, que se volta para todas as suas necessidades privadas.

Entre as forças que movem o coração humano, algumas das mais poderosas parecem situar-se fora dele, não se dirigindo, portanto, como simples meios ao interesse egoísta [auf die Eigennutzlicbkeit] e à necessidade privada, como uma meta que se encontra no interior

25. Idem, p. 333.

26. Idem, p. 334. 
do próprio homem, mas fazem com que as tendências de nossas emoções tenham o foco de sua reunião fora de nós em outros seres racionais, o que gera o conflito de duas forças, a do egoísmo [Eigenheit], que reporta tudo a si mesma, e a do altruísmo [der Gemeinnutzigkeit], o meio pelo qual o coração é dirigido no sentido de outros. ${ }^{27}$

Kant deseja sublinhar o caráter dessa experiência. Diferente da concepção da ética alemã tradicional, tal experiência não acontece a partir de uma intuição racional baseada em nossos juízos acerca do bem e do verdadeiro ${ }^{28}$. Em suas palavras, não se trata de "uma tendência secreta em comparar aquilo que se conhece como bom e verdadeiro por si mesmo com o juízo de outros, para tornar ambos unânimes, e ao mesmo tempo para deter cada alma humana no caminho do conhecimento [...]". ${ }^{29}$ Embora o "entendimento humano universal" não seja sem importância, sendo concebido como "um modo de dar ao todo dos seres pensantes um tipo de unidade racional", o caso específico ao qual se refere Kant diz respeito a uma experiência prática baseada tão somente na tendência autotranscendente da vontade, que revela a existência de uma regra inerente a si própria capaz de - em contrapartida às suas inclinações particulares - proporcionar um modo de orientação aos seres racionais, estabelecendo-se como um princípio de obrigação moral.

[...] o ponto de onde convergem as linhas que direcionam nossos impulsos não se encontra, portanto, somente em nós, mas existem forças que nos movem e são encontradas na vontade de outros fora de nós. Disso nascem os impulsos morais, que, frequentemente, agem contra os comandos do interesse próprio, a forte lei da obri-

27. Idem, ibidem.

28. Neste ponto, Kant parece destacar esta experiência em contraste à ideia de volição da ética intelectualista wolffiana. Wolff acreditava que a vontade nasce da representação que temos da perfeição, que vem acompanhada do prazer. Para ele, não existe uma faculdade volitiva independente, mas, em vez disso, uma faculdade de desejar baseada nos vários graus de clareza do entendimento de acordo com os quais a perfeição é percebida. A intuição intelectual do bem é a condição para desejá-lo e o caminho tanto para a virtude quanto para a felicidade. BECK, L. Early German Pbilosopby. Kant and His Predecessors. Cambridge, Mass.: Harvard University Press, 1969, p. 401.

29. KANT, I. Träume eines Geistersebers, erläutert durcb Träume der Metapbysik, p. 334. 
gação [Scbuldigkeit] e a lei mais fraca da benevolência, cada uma das quais nos arranca muitos sacrifícios e embora, às vezes, as inclinações superem ambas, elas nunca deixam de provar sua realidade na natureza humana. Através disso, vemo-nos, em nossos motivos mais secretos, dependentes de uma regra da vontade universal [abbängig von der Regel des allgemeinen Willens]. ${ }^{30}$

A obrigação moral da qual fala Kant é derivada do princípio ao qual ele chama de regra da vontade universal ${ }^{31}$. É em torno dela que é possível supor uma "unidade moral" como uma "constituição sistemática segundo leis puramente espirituais" ${ }^{1 / 32}$. Schilpp observa que, "ao falar de uma unidade moral resultante como uma condição sistemática conforme leis puramente mentais ${ }^{1133}$, Kant deixa transparecer a ideia geral de seu formalismo. O mundo moral é destituído de conteúdo empírico, sendo constituído exclusivamente pelos aspectos inteligíveis da vontade. Assim, uma vontade é boa em si quando é pura, estando em contraste com a vontade restringida a um bem específico. De acordo com Heinrich, a necessidade da distinção entre estes dois modos de se conceber a vontade conduziu Kant a pensar em uma regra formal de avaliação capaz de reconhecer um modo diferente de volição que não está baseado no êxito de suas realizações. A tentativa de empreender esta distinção foi então o que "[...] deu origem ao imperativo categórico no ano de $1765^{\prime \prime} .{ }^{34}$ Uma vez que a vontade boa em si é destituída de conteúdo, não pode estar submetida a qualquer aspecto empírico, à rede do tempo e da mudança, orientando-se somente a partir das regras de seu próprio âmbito. Por este motivo, a vontade, na hipótese do mundo espiritual, deve se desvincular da natureza. $\mathrm{Na}$

30. Idem, p. 335.

31. Esta concepção é claramente derivada de Rousseau, no entanto, como nos indica SCHILPP (La Ética Pré-Crítica de Kant. Cidad Universitária: Universidad Nacional Autónoma de México, 1966, p. 98.) ao falar de leis espirituais, Kant vai muito além de Rousseau. Schneewind (A Invenção da Autonomia: uma bistória da filosofia moral moderna. São Leopoldo: Editora Usisinos, 2001) também acredita que, embora Rousseau tenha influenciado Kant, a concepção kantiana não está, de modo algum, limitada à dele.

32. Idem, Ibidem.

33. SCHILPP, P. La Ética Pré-Crítica de Kant, p. 98.

34. HENRICH, D. Über Kants früheste Ethik. Kant-Studien, v. 54. Berlin: de Gruyter, 1963, p.406. 
"ordem da natureza" toda a moralidade das ações nunca pode ter "seu efeito consumado plenamente na vida corpórea do homem". ${ }^{35}$ As "verdadeiras intenções, os motivos secretos de muitos esforços infrutíferos por causa da impotência, a vitória sobre si mesmo ou por vezes a deslealdade escondida em ações aparentemente boas são em grande parte perdidos para o resultado físico do mundo corporal" . ${ }^{36}$ Portanto, a "moralidade da ação [das Sittliche der That] diz respeito ao estado interno do espírito", ${ }^{37}$ sendo somente capaz "de exercer ou receber de modo recíproco um efeito adequado à constituição moral do livre arbítrio [freien Willkür]" no mundo dos espíritos, "de acordo com leis pneumatológicas em consequência da conexão da vontade particular e da vontade universal". ${ }^{38}$

É observável que o conceito de uma vontade pura, neste contexto, pressupõe a capacidade da vontade de ser autônoma. Esta concepção inicial de autonomia, como no período posterior, designa a relação da vontade com a lei incondicionada à qual se impõe (e é válida para a vontade de todo ser racional), mostrando, por um lado, a capacidade de autodeterminação da vontade e, por outro, o seu poder de desvinculação de tudo que não seja ela mesma. Portanto, respectivamente, temos, a partir da hipótese do mundo espiritual, as primeiras indicações do conceito que, mais tarde, seria chamado por Kant de liberdade em sentido positivo e negativo ${ }^{39}$, bem como a emergência da ideia geral do formalismo e do imperativo categórico. Esta hipótese ganha ainda mais força quando nos remetemos às anotações

35. Kant, I. Träume eines Geistersebers, erläutert durcb Träume der Metapbysik, p. 336.

36. Idem, Ibidem.

37. Idem, ibidem.

38. Idem, ibidem.

39. Sobre o conceito de liberdade em seus dois sentidos, fala Kant na Crítica da Razão Prática: "Com efeito, é na independência de toda matéria da lei (isto é, de um objeto desejado) e, ao mesmo tempo, na determinação do livre-arbítrio por meio da forma legisladora universal comum, de que toda máxima deve ser capaz, que consiste o princípio único da moralidade. Contudo, essa independência é liberdade em sentido negativo, enquanto esta legislação própria da razão pura e, como tal, prática, é liberdade em sentido positivo. Portanto, a lei moral expressa nada mais do que a autonomia da razão prática pura, ou seja, a liberdade [...]" (KANT, I. Kritik der praktischen Vernunft. In: Gesammelte Scbriften. Berlim: Preußischen Akademie der Wissenschaften, 1910, vol.V, p. 33). 
anexas de Kant em seu exemplar de trabalho de Observações sobre o Sentimento do Belo e do Sublime, nomeadas Bemerkungen, datadas dessa época. Algumas delas nos mostram que essas concepções realmente vinham sendo amadurecidas no período contextualizado entre 1764 e 1766 .

De um modo bastante similar, as anotações trazem a concepção de que a perfeição moral ou a boa vontade está relacionada a uma disposição interna da vontade orientada para a satisfação não só de suas próprias carências, mas dirigida para fora de si, na direção de outros seres racionais. Nesse sentido, Kant revela: "[...] o homem é perfeito na medida em que pode sentir a falta, tendo ainda muita força para promover a necessidade e a felicidade de outros; assim, ele tem o sentimento de uma vontade ativa na direção de um bem fora de $\mathrm{si}^{\prime \prime}{ }^{40}$ A perfeição ou a bondade em si, desse modo, é possível através da capacidade de autotranscendência da vontade, o que significa que a vontade é boa e perfeita na medida em que transcende a sua condição particular e age de acordo com o bem-estar em geral. É deste modo que ela se revela como uma vontade livre. Sobre isso, escreve Kant: "A vontade é perfeita na medida em que, de acordo com as leis da liberdade, é o maior fundamento do bem em geral" $^{\prime 41}$. Agir livremente, diz Kant, é agir adequando a vontade particular à universal sem qualquer contradição. Ele escreve: "em caso de conflito, a vontade universal é mais importante do que a individual". ${ }^{42}$ Nesse ponto, como Rohlf observa, Kant começa a esboçar uma tentativa de derivar "a lei universal e aplicar o teste da contradição" ${ }^{\prime \prime 3}$, o que seria apresentado efetivamente na Fundamentação. Em suas palavras: "[...] a vontade dos seres humanos deveria se contradizer se ela quisesse rejeitar a vontade universal" ${ }^{44}$ E ele segue: "Aquela vontade deve ser boa de modo que não se anule se for tomada universalmente e reciprocamente" ${ }^{45}$

40. KANT, I. Handschriftlicher Nachlass. In: Gesammelte Schriften. Berlim: Preußischen Akademie der Wissenschaften, 1910, vol. XX, p. 146.

41. Idem, pp. 136-137.

42. Idem, p. 161

43. ROHLF, M. Kant’s Early Ethics. American Dialectic, v.1, n.1, 2011, p. 147.

44. KANT, I. Handschriftlicher Nacblass. In: Gesammelte Schriften. Berlim: Preußischen Akademie der Wissenschaften, 1910, vol.XX, p. 161.

45. Idem, p. 67 


\section{No mundo dos espíritos como protótipo do Reino dos Fins}

O conceito de autonomia implícito na hipótese de Sonbos torna plausível supor que a ideia do mundo espiritual é uma formulação inicial do conceito de reino dos fins $^{46}$ das Fundamentações. As duas formulações aproximam-se, uma vez que apresentam a ideia de uma comunidade na qual seus membros estão vinculados mediante leis comuns, que se justificam a partir da capacidade da vontade em se estabelecer como regra universal. O conceito maduro de reino dos fins advém do Imperativo Categórico, que leva em consideração três pontos fundamentais, sendo que os dois primeiros, a saber, a universalidade (a capacidade das máximas de se tornarem lei universal) ${ }^{47}$ e o conteúdo (o ser racional como um fim em si) ${ }^{48}$, subsumem-se na ideia de autonomia ${ }^{49}$ (na qual o ser

46. "Por reino entendo a ligação sistemática de vários seres racionais por meio de leis comuns. Uma vez que leis determinam quais fins têm validade universal, se nos abstraímos das diferenças pessoais dos seres racionais e, então, de todo conteúdo de suas necessidades privadas, podemos pensar uma totalidade de todos os fins em uma conexão sistemática (uma totalidade de seres racionais como fins em si, bem como, uma totalidade dos fins que cada um pode propor a si mesmo). Este é o reino dos fins que pode ser pensado como possível através dos princípios acima" (KANT, I. Grundlegung zur Metaphysik der Sitten. In: __ Gesammelte Schriften. Berlim: Preußischen Akademie der Wissenschaften, 1910, vol. IV, p. 438.)

47. A ideia de reino dos fins está inserida dentro da fórmula do Imperativo Categórico. O imperativo categórico admite três variações que, segundo Kant, são diferentes caminhos para se expressar a mesma lei. Na primeira formulação, "Age só segundo máxima tal que possas ao mesmo tempo querer que ela se torne lei universal" (Idem, p. 421), está indicada sua forma e caráter universal.

48. A segunda formulação do Imperativo Categórico representa seu conteúdo. Ela expressa a fórmula da humanidade: "age de tal maneira que possas usar a bumanidade, tanto na tua pessoa como na pessoa de outro, sempre como um fim e nunca como meio" (Idem, p. 429). Kant explica que a segunda fórmula exalta os seres racionais, dotados de vontade e liberdade, com efeito, seres dotados de valor em si ou dignidade. Em outros termos, estes seres equivalem a um fim em si mesmo.

49. "O conceito segundo o qual todo ser racional deve se considerar, por todas as máximas de sua vontade, o legislador universal $[\ldots]$, conduz a outro conceito bastante fecundo que lhe pode ser relacionado, o conceito de reino dos fins [Reich der Zwecke]" (Idem, p. 438). 
racional dotado de vontade promulga sua própria lei $)^{50}$. Portanto, o reino dos fins, como o conceito de uma união sistemática de diferentes seres racionais, só é possível por causa da capacidade de suas máximas de se estabelecerem, descontadas de seus fins particulares, como uma lei universal. Não existe nenhuma diferença substancial em relação ao conceito do mundo espiritual. Este, de uma maneira bastante similar, é baseado na ideia de que a vontade é capaz de estabelecer uma regra por si própria, que supera as inclinações privadas, para estar de acordo com o consenso universal da vontade. Sendo assim, a regra da vontade universal é o que torna possível que seres independentes, "princípios espontâneos" ou "substâncias e naturezas subsistentes por si"51, organizem-se reciprocamente em "uma unidade moral", descrita como um tipo de mundo inteligível ou um sistema segundo leis puramente espirituais. A regra da qual Kant fala nada mais é do que uma antecipação do imperativo categórico, que representa a capacidade dos seres racionais de agir como seres autônomos e de se organizar exatamente em torno desta característica comum.

O conceito de reino dos fins ainda nos apresenta outro aspecto muito importante que pode ser retirado da primeira formulação do imperativo categórico: a ideia de que seu caráter universal é posto junto à referência de um sistema da natureza ${ }^{52}$. Kant entende a natureza, em seu sentido mais amplo, como a existência de coisas determinadas por leis. A natureza é algo mais do que uma reunião de coisas, é um conjunto de elementos organizados e sistematizados por leis universais.

50. A terceira fórmula encerra em si as duas primeiras formulações, a saber, o caráter universal contido na fórmula da primeira e o conteúdo que caracteriza a segunda, legitimando o ser racional, dotado de vontade, como um fim em si mesmo. Disso decorre uma fórmula que expressa, com todo vigor, a autonomia dos seres racionais. Estes seres, enquanto dotados de liberdade, só podem ser submetidos a leis se estas forem uma imposição que parte deles próprios. "Disso decorre o terceiro princípio prático da vontade como condição suprema da concordância dessa vontade com a razão prática universal, a saber, a ideia da vontade de todo ser racional concebida como vontade legisladora universal" (Idem, p. 431). A terceira formulação proporciona a Kant o suporte necessário para a articulação do conceito de reino dos fins.

51. KANT, I. Träume eines Geistersebers, erläutert durcb Träume der Metapbysik, p. 329.

52. Dentro da já citada primeira fórmula há uma complementação: "Age como se a máxima da tua ação devesse se tornar, pela tua vontade, lei universal da natureza" (KANT, I. Grundlegung zur Metapbysik der Sitten, p. 421). 
Portanto, a sistematicidade, que caracteriza o universo natural como um todo, deve ser também a referência para o reino dos fins. Esta posição já está delineada, em 1766, quando Kant apresenta uma analogia entre a constituição do mundo dos espíritos, baseada nas regras morais, e a do mundo natural, justificada a partir do princípio newtoniano da gravitação. A ideia da força ativa da atração material, que levou Newton a estabelecer a lei da gravidade e o sistema das coisas naturais, leva Kant a imaginar, de igual modo, uma força de reciprocidade entre seres racionais. Se existe em nível moral-racional, esta força deve ser tão indiscutivelmente universal e tão necessária como a gravidade na esfera física $^{53}$. Ou seja, se a comprovação do fenômeno da gravitação proporciona as bases para que a natureza possa ser compreendida como um sistema próprio mediante leis universais, do mesmo modo, deve ser possível, através do fenômeno moral - comprovado em nossa experiência volitiva - constatar a legitimidade do mundo imaterial, enquanto sistema efetivo e independente de leis universais.

Newton chamou as leis determinadas que regem a tendência de todas as partículas da matéria em se aproximar de gravitação da matéria, sem, no entanto, desejar misturar suas demonstrações matemáticas em possíveis disputas filosóficas preocupadas com as causas das mesmas. Todavia, ele não hesitou em tratar a gravitação como um efeito genuíno produzido por uma atividade universal da matéria operando sobre si e por esta razão a chamou de atração [Anziehung]. Então, por que deveríamos supor que, do mesmo modo, não seja possível representar os fenômenos dos impulsos morais em naturezas pensantes, que reciprocamente se relacionam umas com as outras, como um efeito de uma força genuinamente ativa, em virtude da qual naturezas espirituais exercem uma influência em outras substâncias? [...] Seria em função desta reciprocidade que o mundo imaterial deveria alcançar a unidade moral como resultado de ter formado um sistema de perfeição espiritual de acordo com leis de uma conexão própria. ${ }^{54}$

A ideia de um mundo espiritual segundo leis morais representa uma tentativa de proporcionar uma resposta ao importante problema ético, com o qual Kant estava preocupado, representado na necessidade de se esclarecer como é possível estabelecer a liberdade humana

53. SCHILPP, P. La Ética Pré-Crítica de Kant, p. 100.

54. KANT, I. Träume eines Geistersebers, erläutert durcb Träume der Metapbysik, p. 335. 
da vontade mediante a um princípio de obrigação incondicionado. Trata-se, em outras palavras, da questão de como os seres morais, concebidos como agentes livres, podem existir dentro do mundo natural, sem estarem submetidos por suas leis determinísticas ou por seus aspectos empíricos. A solução, como Johnson aponta, foi "a divisão do cosmos dentro de dois reinos distintos, o mundo natural, governado pelas leis físicas, e o mundo espiritual, governado pelas leis morais". ${ }^{55}$ Desse modo, foi possível garantir a participação do homem no mundo espiritual, na medida em que ele existe como um ser dotado de vontade, sem contradizer sua existência como ser corpóreo no mundo natural. Mas, para isso, foi preciso considerar que, embora ambos sejam reinos distintos conduzidos por leis específicas, podem mutuamente se relacionar. Dessa forma, foi possível conceber a liberdade da vontade como um tipo de causalidade incondicionada, capaz de ter parte de seus efeitos vislumbrados no mundo sensível. Ao mesmo tempo, foi possível proporcionar a fundação de um conceito incondicionado de obrigação moral, baseado em aspectos racional-inteligíveis, capaz de se ligar adequadamente aos aspectos concretos da conduta, que são empírico-afetivos, sem perder sua necessidade. Este foi o caminho encontrado por Kant para solucionar a sua dúvida sobre a fundação dos primeiros princípios da obrigação moral. A ideia de uma metafísica da moral foi o advento capaz de responder à questão, superando, por um lado, o intelectualismo exacerbado dos seguidores de Wolff - que tratavam a vontade como um aspecto abstrato do entendimento - e, por outro, o psicologismo dos empiristas britânicos - incapaz de proporcionar um fundamento incondicionado para a ética e explicar a experiência da liberdade para além do fato psicológico.

\section{O papel do sentimento moral em Sonhos}

O tema da obrigação moral foi tratado pela primeira vez por Kant, em 1764, no ensaio intitulado Investigação sobre a Evidência dos Princípios da Teologia Natural e da Moral, popularmente conhecido como Ensaio Premiado [Preisschrift]. Neste trabalho, Kant apresentou, de forma enfática, a sua posição em relação ao estado presente do pensamento ético: "desejo apenas mostrar quão pouco ainda é conhecido mesmo

55. JOHNSON. G. From Swedenborg's Spiritual World to Kant`s Kingdom of Ends. Aries Journal, Boston: Brill, 2009, p. 90. 
o conceito primário de obrigação e quão longe se deve estar, portanto, de fornecer, na filosofia prática, a clareza, necessária para a evidência, e a segurança dos conceitos fundamentais e princípios [Grundbegriffe und Grundsätze]"56.

No Ensaio, Kant mostra-se ciente que uma regra da obrigação torna-se problemática quando condicionada por um fim determinado. Kant diz "[...] todas as ações são contingentes na medida em que a moral as dita sob as condições de determinados fins e não podem ser chamadas de obrigação enquanto não forem subordinadas a um fim necessário em si". ${ }^{77}$ Assim, toda regra da obrigação deve comandar e prescrever a obrigação de forma imediata, não se relacionando a um fim ou a condições estabelecidas ${ }^{58}$. Desse modo, Kant admite a necessidade de se considerar um princípio formal como regra da obrigação expressa na seguinte fórmula positiva ${ }^{59}$ : "Faças o que há de mais perfeito". ${ }^{60}$ Todavia, embora o princípio formal deva representar a obrigação, parece insuficiente para determinar obrigações específicas. Por isso, Kant é levado a reconhecer que "nada decorre dos primeiros princípios formais de nossos juízos sobre o verdadeiro, se não forem dados fundamentos materiais; muito menos alguma obrigação particularmente determinada decorre dessas duas regras do bem, se a elas não estiverem vinculados princípios materiais indemonstráveis do conhecimento prático" ${ }^{61}$ Portanto, a existência de princípios práticos materiais representados na "capacidade de [...] experimentar a sensação

56. KANT, I. Untersucbung über die Deutlichkeit der Grundsätze der natürlichen Theologie und der Moral. In: Gesammelte Scbriften. Berlim: Preußischen Akademie der Wissenschaften, 1910, vol. II, p. 298.

57. Idem, ibidem.

58. Kant toma esse conceito de obrigação de Crusius, que, em contraposição às concepções da ética dos Wolffianos, defendia que a necessidade moral é diferente da necessidade de nossos fins contingentes. Crusius distingue obrigação de prudência e obrigação de virtude. A última torna a ação necessária desconsiderando os fins, pois, existem certas leis incorporadas na vontade que movem o ímpeto para ação sem precisar de um estímulo externo.

59. Kant apresenta também o enunciado negativo desse princípio formal: "Abstenha-se do que o impede da maior perfeição possível [...]" (idem, p. 299).

60. Idem, p. 299

61. Idem, ibidem. 
do bem", ${ }^{62}$ deve ser levada em conta, caso se queira entender como a conduta moral concreta pode ser explicada. Kant está convicto, de acordo com "Hutcheson e outros", que existe "um ponto de partida para belas observações" situado no conceito daquilo que se entende pelo "nome de sentimento moral [des moralischen Gefübls]"63.

Dentro da literatura secundária, essas foram algumas das evidências que conduziram à hipótese de que o pensamento ético de Kant de 1760 foi meramente a expressão da doutrina do sentimento moral, como apreendida através dos ingleses ou de Rousseau. Os comentadores estiveram convictos, por muito tempo, que o rompimento efetivo com esta doutrina aconteceu somente por volta dos anos de 1770, como indicam as evidências da Dissertação e das Reflexiones. Na Dissertação, Kant apresenta definitivamente a razão pura como o elemento determinante na concepção dos princípios e juízos morais. Por conseguinte, nas Reflexionen desse período é possível observar que o sentimento moral não é tratado como tendo uma função determinante em relação ao princípio da moral. O sentimento nem mesmo pode ser considerado um aspecto original e a sua doutrina aparece mais como "uma hipótese para explicar o fenômeno da aprovação de que damos a alguns tipos de ação, do que como um intento de estabelecer máximas e princípios primeiros que sejam objetivamente válidos" ${ }^{\prime \prime}$ Assim, a partir das Reflexiones, parece claro que "[...] o juízo moral não se origina do sentimento, mas este daquele. Todo sentimento moral pressupõe juízo moral através do entendimento". 65 "Na relação do fim nada pode dar regras universais do emprego da liberdade exceto a razão pura". ${ }^{66}$

Todavia, a década anterior nos dá acesso a algumas evidências que apoiam a suposição de que o papel do sentimento moral dentro da ética já estava devidamente delimitado desde meados de 1760. Para começar, o Ensaio Premiado, uma das referências para a interpretação tradicional, não proporciona nenhuma prova conclusiva de que Kant tenha assumi-

62. Idem, ibidem.

63. Idem, p. 300.

64. KANT, I. Handschriftlicher Nachlass. In: Gesammelte Schriften. Berlim: Preußischen Akademie der Wissenschaften, 1910, vol. XIX, pp. 116-117 (Rx 6626).

65. Idem, p.152 (Rx 6760).

66. Idem, p.211 ( $\mathrm{Rx} 6948)$. 
do a doutrina do sentimento moral como fundamento da ética. Embora os moralistas ingleses apareçam em destaque e o sentimento seja apontado como um possível recurso para se alcançar obrigações específicas, as palavras finais de Kant, no Ensaio, vão contra o que a perspectiva tradicional defendeu. Ao final do Ensaio, Kant se mostra em um claro estado de dúvida em relação às bases sobre as quais a obrigação moral deve se fundar: será o conhecimento ou o sentimento?

[...] Disto deve se observar que, se deve ser possível alcançar o maior grau de evidência filosófica nos primeiros fundamentos da moralidade, os conceitos supremos da obrigação devem, primeiramente, ser definidos de modo seguro [...], devendo ser decidido, antes de tudo, se é meramente a faculdade de conhecimento ou o sentimento [Erkenntnissvermögen oder das Gefübl] (o fundamento primário interno da faculdade de desejar [Begebrungsvermögens]) que decide os princípios primários da filosofia prática. ${ }^{67}$

Ademais, é possível observar nas Bemerkungen os esboços de uma tentativa de compreender a questão de modo diferente. De acordo com Schmucker, o conceito de sentimento moral apresentado nas anotações é diferente do enunciado por Rousseau. O sentimento moral, para Rousseau, consiste na extensão do amor próprio às outras pessoas com as quais nos identificamos. Essa forma de sentimento é uma instância atrelada ao particular, próxima ao sentimento físico. ${ }^{68} \mathrm{Na}$ concepção que se configura em Bemerkungen, existe um princípio de universalização que proporciona um status especial ao sentimento moral, identificado-o com a natureza categórica e não hipotética da obrigação. ${ }^{69}$ Este princípio está estabelecido, como destacamos, a partir da única condição sobre a qual os conceitos de obrigação e de felicidade são realmente possíveis, ou seja, a partir da regra da vontade de acordo com o consenso universal. "A bondade da vontade é derivada da utilidade privada ou pública". ${ }^{70}$ Mas, no que concerne à

67. KANT, I. Untersuchung über die Deutlichkeit der Grundsätze der natürlichen Theologie und der Moral, p. 300.

68. SCHMUCKER, J. Die Ursprünge der Etbik Kants, p. 198.

69. SHELL, S. The Embodiment of Reason: Kant on Spirit, Generation, and Community. Chicago: University of Chicago Press, 1996, p. 103.

70. KANT, I. Handschriftlicher Nachlass. In: Gesammelte Schriften. Berlim: Preußischen Akademie der Wissenschaften, 1910, vol. XX, p. 156. 
primeira, se surge "oposição e contradição, então a ação desagrada", de outro modo, em relação ao último, se "surge harmonia e consenso" e, então, as ações agradam. Portanto, "O sentimento de prazer e desprazer concerne a algo, com respeito ao qual [...] somos passivos, que é um principium ativo do bem e do mal através da liberdade" ${ }^{.71} \mathrm{Em}$ outras palavras, os sentimentos do prazer e do desprazer não são mais que o resultado da atividade de nossa vontade de acordo com as leis da liberdade. Por sua vez, o sentimento moral não é mais do que "[...] um sentimento oriundo da perfeição da vontade [Vollkommenbeit des Willens]". ${ }^{72}$

Este tratamento dado ao tema, como é possível verificar, emerge na hipótese do mundo espiritual. Ao iniciar sua exposição, Kant chama a atenção para a experiência através da qual percebemos um "arbítrio externo [fremder Willkür]", responsável por nos conduzir ao "consentimento externo [äusserer Bestimmung]" e nos coagir "a orientar nossa intenção para o bem-estar de outros [...] mesmo que isso aconteça contra nossa vontade e se oponha fortemente à inclinação egoísta" ${ }^{73}$ Esta estranha sensação manifesta-se como um tipo de coerção que percebemos nas ações em que priorizamos os desígnios de nossa vontade particular, mostrando-nos que estamos submetidos, por nossa própria vontade, a uma regra. É como um freio externo ou alheio a nós que percebemos na ação, complementa Schneewind. ${ }^{74}$ Kant tem um nome para esta experiência: "Se quer chamar de sentimento moral essa coerção [Nötbigung] sentida de nossa vontade para a concordância da vontade universal, então se fala disso apenas como de uma manifestação daquilo que se passa efetivamente em nós [...]. ${ }^{75} \mathrm{~A}$ hipótese do sentimento dentro do mundo espiritual, como salienta Schneewind ${ }^{76}$, dá continuidade às tentativas de Kant de entender o sentimento moral a partir de algo distinto do naturalismo determinista de Hutcheson, que concebia o amor próprio e a benevolência como as forças que ordenavam a constituição do mundo moral. Para Schilpp, ao delimitar mais precisamente a função do sentimento dentro da ética, Kant o

71. Idem, p. 146.

72. Idem, p. 137.

73. KANT, I. Träume eines Geistersehers, erläutert durcb Träume der Metapbysik, p. 334.

74. SCHNEEWIND, J. A Invenção da Autonomia, p. 550.

75. KANT, I. Träume eines Geistersebers, erläutert durcb Träume der Metapbysik, p. 335.

76. SCHNEEWIND, J. A Invenção da Autonomia, p. 550. 
apresenta como um sentimento de dependência. "[...] o sentimento moral seria essa dependência sentida da vontade privada diante da vontade universal e uma consequência da ação recíproca natural e universal através do qual o mundo imaterial ganha sua unidade $[\ldots]^{\prime \prime}$. Assim, Kant reconhece que há "um elemento reflexivo ao mesmo tempo em que um emocional". ${ }^{77}$ Mas, parece claro que o elemento emocional ou psicológico, mesmo reconhecido como um aspecto importante da vida moral, sempre será um sentimento de dependência ou uma conseqüência da ação recíproca da vontade, porque as forças motrizes responsáveis pela constituição do mundo moral não encontram suas bases nele, mas na ideia de um mundo espiritual livre, capaz de controlar as disposições morais do homem, tornado-as efetivas no mundo natural.

A delimitação dada por Kant ao conceito, portanto, impõe a ele características que o tornam compatível com o caráter categórico da obrigação. Não se trata, como queria Hutcheson, de um critério natural que permite discriminar razões de nossa sensibilidade que apontam para uma experiência básica de acordo com a qual todas as outras ideias morais são possíveis. Kant não está falando de um senso moral capaz de avaliar nossa experiência de aprovação e reconhecer experiências mais básicas como a da benevolência. O que Kant quer tratar é da ideia de um sentimento que indica nossa experiência de dependência de algo que não é meramente empírico. O sentimento é o modo pelo qual somos coagidos ${ }^{78}$ pela consciência de uma lei interna. É a partir da coação que a lei impõe uma resistência sobre os impulsos do

77. SCHILPP, P. La Ética Pré-Crítica de Kant. p. 99.

78. Nas linhas da Critica da Razão Prática, de um modo similar, a relação de nossa vontade com a lei apresenta-se através da consciência de subordinação e dependência. Esta consciência se manifesta porque a razão prática exerce, através da lei, constrangimento sobre a vontade, proporcionando um efeito que se faz sentir em nossa sensibilidade. Este é o modo encontrado pela razão de coibir, através de um sentimento intelectual, a vontade afetada, mostrando-lhe a força do imperativo moral. "Para os homens, a lei moral, enquanto lei incondicionada, é um imperativo que manda categoricamente. A relação da vontade com a lei se manifesta como dependência [Abbändigkeit] que, sob o nome de obrigação [Verbindlicbkeit], indica um constrangimento [Nötbigung] em relação ao dever [...] porque um livre arbítrio [Willkür] patologicamente afetado [...] pode por isso opor-se constantemente ao puro fundamento objetivo, necessitando, por conseguinte, de um constrangimento moral ou 
mundo natural, depurando-os da experiência de nossa vontade. Portanto, estas características básicas permitem-nos afirmar que o sentimento moral que Kant traz à luz nesse momento é uma instância bem próxima ao moralisches Gefübl ${ }^{79}$ da Crítica da Razão Prática, conhecido também como "estranho sentimento de respeito" ${ }^{80}$

\section{Considerações Finais}

Levando em conta o assunto tratado aqui, é considerável que o estudo da gênese da ética kantiana é um requisito importante, não somente para fins de reconstrução histórica, mas, também, para um entendimento mais completo e adequado de todo o sistema. O edifício inovador da ética crítica, iniciado, de modo efetivo, no ano de

uma resistência da razão prática, resistência a qual pode ser denominada uma coerção [Zwang] intelectual" (KANT, I. Kritik der praktischen Vernunft, p. 32).

79. Sabe-se que a hipótese do sentimento moral que existe na ética crítica é uma tentativa de Kant estabelecer um teoria do sentimento compatível com a ideia de uma moral pura, por isso, ele aparece como a teoria do sentimento de respeito [Acbtung]. Este é definido como uma atividade racional, intelectual, que determina a submissão da vontade à lei. Não se trata de uma inclinação [Neigung], mas de uma atividade que determina a coerção da vontade diante do dever. A faculdade da razão é capaz de liberar uma causalidade que determina a sensibilidade conforme seus princípios. Como consequência, temos acesso a um sentimento que Kant denomina como "algo meramente subjetivo, um sentimento de tipo especial, que não é um juízo sobre um objeto [...]" (KANT, I. Die Metapbysik der Sitten. In: Gesammelte Schriften. Berlim: Preußischen Akademie der Wissenschaften, 1910, vol. VI, p. 403). "[S]entimento que por alguns filósofos foi apresentado de maneira errada como padrão de nosso juízo moral, quando parece correto que ele deve ser tomado como efeito subjetivo que a lei exerce sobre a vontade, cujos fundamentos objetivos apenas a razão conhece" (KANT, I. Grundlegung zur Metapbysik der Sitten, p. 460). Dessa forma, quando se fala de sentimento moral no período crítico, Kant não está tratando de algo propriamente sensível, mas de uma determinação que se origina a priori do âmbito prático. "Aquilo que reconheço imediatamente para mim como uma lei, reconheço com respeito, e este respeito significa somente a consciência da subordinação da minha vontade a uma lei, sem a mediação de outras influências no meu sentir. A determinação imediata da vontade pela lei e a consciência da mesma chama-se respeito: de modo que é considerado como efeito da lei sobre o sujeito e não como causa" (Idem, p. 428).

80. JOHNSON, G. Kant on Swendenborg, p. 163. 
1785, através das Fundamentações da Metafísica dos Costumes e complementado por outros trabalhos de igual calibre como a Crítica da Razão Prática, de 1788, e a Metafísica dos Costumes, de 1797, pode ser mais bem compreendido quando se tem em mente os problemas que Kant precisou superar em sua reflexão ética inicial. Embora, neste artigo, tenhamos tratado estes problemas de maneira superficial, limitando-nos a mostrar como alguns conceitos apareceram, é perceptível que o desenvolvimento destes conceitos foi uma resposta às questões, enunciadas sobre a possibilidade de uma interpretação incondicionada dos conceitos de obrigação moral e de liberdade, que não foram adequadamente resolvidas pelos predecessores de Kant. De fato, os primeiros insights em direção às respostas relacionadas ao problema ético, que seriam divulgadas apenas no período crítico, já estavam implícitos no contexto da reflexão inicial. Assim, é imposta a necessidade de tratar os textos iniciais com um maior cuidado e respeito, porque eles são capazes de nos revelar muito sobre a dinâmica do pensamento kantiano, como foi possível observar através da referência ao texto de 1766 Sonbos de um Visionário - considerado pela literatura secundária, por muito tempo, como um trabalho irrelevante. De fato, Sonbos representou um momento determinante no desenvolvimento intelectual kantiano, no qual Kant percebeu mais profundamente a necessidade de superar problemas fundamentais deixados pela tradição, bem como de reavaliar o status de sua própria filosofia. Seu significado verdadeiro não se restringe àquela roupagem exterior, caracterizada nas histórias sobrenaturais sobre espíritos, no tom jocoso e irreverente, nos recursos linguísticos ou no ceticismo, mas em um núcleo interno, subjacente, representado em questões de caráter teórico e prático para as quais as respostas seriam determinantes, nos anos seguintes, para os rumos da filosofia crítica. Podemos afirmar, com base em algumas questões iniciais, que, no lugar de descontinuidade, a reflexão pré-crítica, principalmente a ligada à ética, apresenta um lento e penoso desenvolvimento de perspectivas.

\section{Referências Bibliográficas:}

BECK, L. Early German Pbilosopby. Kant and His Predecessors. Cambridge, Mass.: Harvard University Press, 1969.

BEISER, F. Kant`s Intellectual Development. In: GUYER, P. (org.) The Cambridge Companion to Kant. United Kingdom: Cambridge University Press, 1992, pp. 26-57. 
CUNHA, B. Sobre a questão do espírito: Sonbos de um Visionaries e sues contribuições para a ética crítica de Kant. Dissertação, UFJF. Juiz de Fora, 2011.

HENRICH, D. Über Kants früheste Ethik. Kant-Studien. v. 54. Berlin: de Gruyter, 1963, pp. 404-431.

JOHNSON, G. From Swedenborg's Spiritual World to Kant’s Kingdom of Ends. Aries Journal, Boston: Brill, 2009.

Kant on Swendenborg: Dreams of Spirit-seer and other writings. United States: Swendenborg Foundation, 2002.

KANT, Immanuel. Escritos Pré-Críticos. São Paulo: Ed. UNESP, 2005. .Immanuel Kants gesammelte Schriften. Edit. Akademie der Wissenschaften. V.I-XXI. Berlin: Reimer (later DeGruyter), 1910.

ROHLF, M. Kant's Early Ethics. American Dialectic, v.1, n.1, 2011, pp. $137-166$.

SCHNEEWIND, J. A Invenção da Autonomia: uma bistória da filosofia moral moderna. São Leopoldo: Editora Usisinos, 2001.

SCHILPP, P. La Ética Pré-Crítica de Kant. Cidad Universitária: Universidad Nacional Autónoma de México, 1966.

SCHMUCKER, J. Die Ursprünge der Etbik Kants in seinen vorkritischen Scbriften und Reflektionen. Meisenheim: A. Hain, 1961.

SHELL, S. The Embodiment of Reason: Kant on Spirit, Generation, and Community. Chicago: University of Chicago Press, 1996. 